\title{
Cheyne-Stokes respiration and supine dependency
}

\author{
C. Sahlin*, E. Svanborg", H. Stenlund" and K.A. Franklin*
}

ABSTRACT: The influence of position during sleep on central apnoeas during Cheyne-Stokes respiration has not previously been studied systematically. The current authors aimed to study the effect of body position and sleep stages on central sleep apnoeas during Cheyne-Stokes respiration.

A total of 20 consecutive patients with cardiovascular diseases and central sleep apnoea during Cheyne-Stokes respiration were investigated using nocturnal polysomnography, including a body position sensor mounted on the patient's sternum.

The mean central apnoea-hypopnoea index was significantly higher in the supine position than in nonsupine positions ( $41 \pm 13$ versus $26 \pm 12)$. The central apnoea-hypopnoea index was highest in sleep stages 1 and 2, and lowest in slow-wave sleep and rapid eye movement sleep. In every sleep stage, central apnoeas and hypopnoeas were more prevalent in the supine position compared with nonsupine positions.

In conclusion, sleep in the supine body position increases the frequency of apnoeas and hypopnoeas in patients with Cheyne-Stokes respiration.

KEYWORDS: Cheyne-Stokes respiration, heart failure, polysomnography, sleep apnoea syndromes, supine position

$\mathbf{M}$ any patients presenting with frequent central apnoeas suffer from congestive heart failure and Cheyne-Stokes respiration, with a typical waxing-and-waning breathing pattern followed by a central apnoea [1, 2]. As many as $40 \%$ of males with congestive heart failure suffer from Cheyne-Stokes respiration during sleep, and they have an increased ventilatory response to carbon dioxide tension $\left(\mathrm{PCO}_{2}\right)[3,4]$. During Cheyne-Stokes respiration, there are simultaneous cyclical changes in cerebral blood flow, respiration and wakefulness, followed by changes in heart rate and blood pressure [5]. Central apnoeas and Cheyne-Stokes respiration are most frequent in sleep stages 1 and $2[6,7]$.

It is well known that obstructive apnoeas are most frequent in the supine position [8,9], but the influence of body position on central apnoeas and Cheyne-Stokes respiration has not previously been studied systematically. The current authors aimed to study the effect of body position and sleep stages on central apnoeas during CheyneStokes respiration.

\section{METHODS}

Consecutive patients with central sleep apnoea during Cheyne-Stokes respiration were identified from investigated patients referred for polysomnography under suspicion of sleep apnoea. The inclusion criteria were a central apnoea-hypopnoea index $(\mathrm{AHI})$ of $\geqslant 15$, an obstructive $\mathrm{AHI}$ of $<5$, an arterial carbon dioxide tension $\left(\mathrm{Pa}_{\mathrm{a}} \mathrm{CO}_{2}\right)$ $<6.0 \mathrm{kPa}(<45 \mathrm{mmHg})$ and a typical waxingand-waning respiratory pattern between the central apnoeas (fig. 1). Six patients were excluded as they slept for $<20 \mathrm{~min}$ in either the lateral or the supine position, while two were excluded because their body position sensor was lost during polysomnography. A total of 20 consecutive patients who fulfilled the criteria were included. Approval for the study was obtained from the Medical Ethics Committee at the University of Umeå (Umeå, Sweden) and all the patients gave their written consent.

Polysomnography included electroencephalogram (C3-A2, C4-A1), electro-oculogram, chin electromyogram, nasal and oral airflow (threeport thermistor), respiratory effort from piezoelectric belts around the abdomen and chest (Resp-EZ; EPM Systems, Midlothian, VA, USA), finger oximetry (Biox 3740; Ohmeda, Monroeville, CO, USA) and electrocardiograms (V5). A body position sensor with a mercury switch and resistive network (Vitalog Monitoring Inc., Redwood City, CA, USA) was placed

\section{AFFILIATIONS}

Depts of *Respiratory Medicine, and "Epidemiology and Public Health, University Hospital, Umeå, and \#Dept of Clinical Neurophysiology, University Hospital, Linköping, Sweden.

CORRESPONDENCE

K.A. Franklin

Dept of Respiratory Medicine

University Hospital

SE-901 85 Umeå

Sweden

Fax: 4690773817

E-mail: karl.franklin@lung.umu.se

Received:

September 162004

Accepted after revision:

January 112005

\section{SUPPORT STATEMENT}

This study was supported by grants from the Swedish Heart and Lung Foundation (Stockholm, Sweden) and the Swedish Association for Heart and Lung Patients (Sollefteå and Umeå, Sweden). 


\section{Supine}

NL Left side

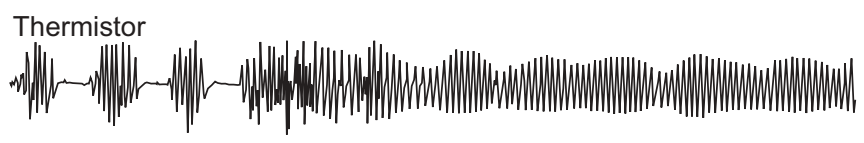

Chest movements

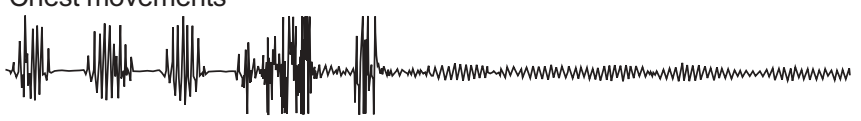

Abdominal movements

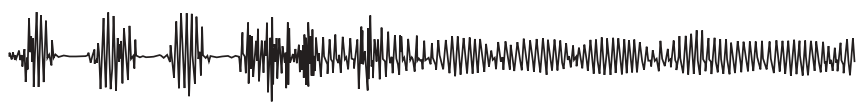

$\mathrm{Sa}, \mathrm{O}_{2}$

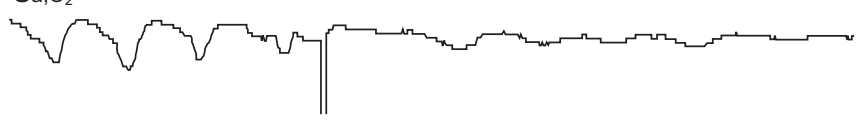

FIGURE 1. Respiratory patterns during sleep in a 59-yr-old male patient suffering from congestive heart failure. Cheyne-Stokes respiration was eliminated when the patient turned from the supine position to the left side. $\mathrm{Sa}, \mathrm{O}_{2}$ : arterial oxygen saturation.

directly on the skin above the sternum with adhesive tape. After calibration, the patient was told to rotate in the bed in order to check that every position was recorded correctly. Arterial blood gases were taken in the supine position during the day after polysomnography.

Sleep stages were scored manually according to RECHTSCHAFFEN and KALES [10]. An apnoea was defined as a cessation of airflow for $\geqslant 10 \mathrm{~s}$ and a hypopnoea as a $50 \%$ reduction in the thermistor tracing compared with baseline, in combination with an arousal, or an oxygen desaturation of $\geqslant 3 \%$ [11]. Cheyne-Stokes respiration was characterised by cyclical fluctuations in breathing, with periods of central apnoeas or hypopnoeas alternating with periods of hyperpnoea in a gradual waxing-and-waning fashion $[1,2,12]$. A central apnoea was scored at the cessation of thoracoabdominal movements, whereas a central hypopnoea was scored when thoraco-abdominal movements decreased parallel to airflow during Cheyne-Stokes respiration [7]. Supine position was scored within a range of $\pm 45^{\circ}$ between the supine and a lateral position.

Data were calculated as the mean $\pm \mathrm{SD}$. The Mann-Whitney Utest was used to compare differences in sleep time. The rank sum test, nonparametrically related, was used to compare AHI in supine and nonsupine positions. A p-value $<0.05$ was considered significant. Friedman's test for related samples was used to compare the AHI in different sleep stages. Wilcoxon rank sum test with Bonferroni correction for multiple comparisons was used as a post hoc test.

\section{RESULTS}

Nineteen of 20 patients were males, aged $65 \pm 15$ (range 19-80) yrs, with a mean body mass index (BMI) of $27 \pm 3 \mathrm{~kg} \cdot \mathrm{m}^{-2}$. Two reported habitual snoring. Eighteen patients suffered from congestive heart failure and two patients with atrial fibrillation had experienced a stroke. The two latter patients had no signs of congestive heart failure, but their respiratory patterns, including Cheyne-Stokes respiration, were identical to those of the remaining patients with central sleep apnoea. The characteristics of patients are given in table 1 and the sleep data are given in table 2 .

The central AHI was higher in the supine position compared with nonsupine positions in 17 out of 20 patients. The mean central AHI was $41 \pm 13$ in the supine position and $26 \pm 12$ in nonsupine positions $(\mathrm{p}<0.001$; fig. 2$)$. The central AHI was $28 \pm 17$ while sleeping on the left side and $25 \pm 17$ on the right side, and both were lower than the AHI in the supine position $(\mathrm{p}<0.001)$. In every sleep stage, central apnoeas and hypopnoeas were more prevalent in the supine position compared with lateral positions (table 3). BMI did not correlate with the postural effect of central sleep apnoea expressed as the ratio of central AHI supine:nonsupine.

Central sleep apnoeas were more frequent in sleep stages 1 and 2 compared with slow-wave sleep and rapid eye movement (REM; $\mathrm{p}<0.001)$. The apnoea frequency in various sleep stages was independent of body position (table 3 ).

The mean duration of central apnoeas, calculated from the mean for each patient, was $26 \pm 8 \mathrm{~s}$. Central apnoeas were shortest during REM $(\mathrm{p}<0.05)$.

\section{DISCUSSION}

The main finding in this study was that central apnoeas and Cheyne-Stokes respiration are supine dependent in nonhypercapnic patients with cardiovascular problems. In a recent case report, it was suggested that Cheyne-Stokes respiration could be supine dependent in conformity with obstructive sleep apnoea [13]. In the present systematic study of patients with Cheyne-Stokes respiration, central apnoeas were found to be supine dependent, which is a novel finding. There is, however, no obvious explanation for the high frequency of central apnoeas in the supine position.

In 1986, ISSA and SULLIVAN [14] presented a case series of eight snoring patients, with a combination of obstructive and idiopathic central sleep apnoea, who were treated with nasal continuous positive airway pressure. These patients had obstructive apnoeas and snoring predominantly in the lateral position, and central and mixed apnoeas in the supine position. They concluded that upper airway collapse in the supine position plays a key role in the induction of central apnoea. BRADLEY et al. [15] observed that five out of 13 overweight snoring patients with idiopathic central sleep apnoeas presented apnoeas exclusively in the supine position. It was suggested that upper airway narrowing may have resulted in sufficient stimulation of upper airway receptors to inhibit central respiratory output. The previous studies included patients with idiopathic central sleep apnoea and clinical signs of increased upper airway resistance. AlEx et al. [16] observed that central apnoeas often terminated with an upper airway occlusion among subjects with Cheyne-Stokes respiration, and BADR et al. [17] demonstrated pharyngeal occlusion during central apnoeas. The current study did not include any patients with idiopathic central sleep apnoea. All of the current patients with central sleep apnoea suffered from Cheyne-Stokes respiration and cardiovascular diseases. They were not obese, none had obstructive sleep apnoea, and only 


\section{TABLE 1 Characteristics of patients}

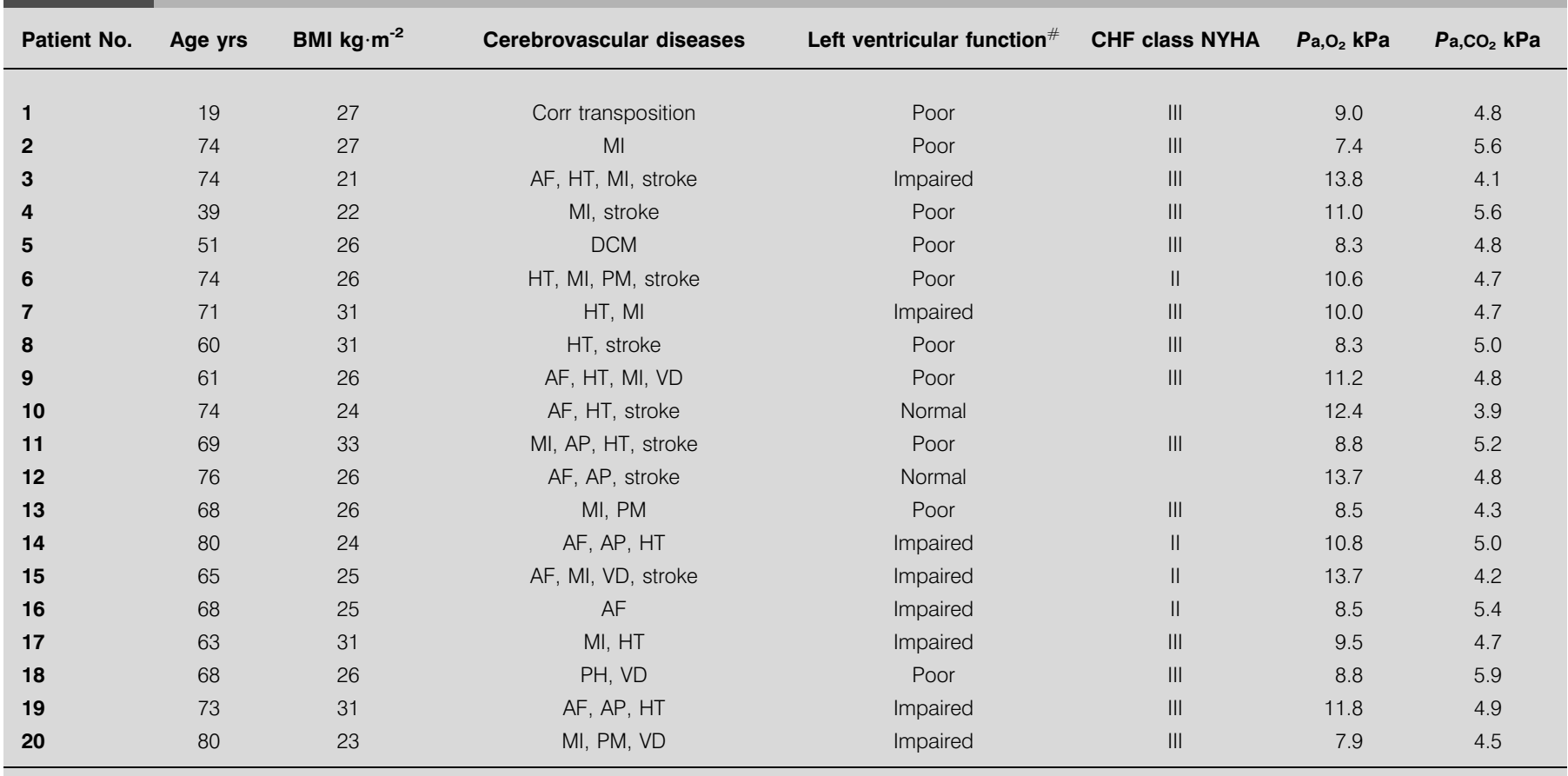

BMI: body mass index; CHF: congestive heart failure; NYHA: New York Heart Association; $\mathrm{Pa}, \mathrm{O}_{2}$ : arterial oxygen tension; $\mathrm{Pa}_{1} \mathrm{CO}_{2}$ : arterial carbon dioxide tension; $\mathrm{MI}$ previous myocardial infarction; AF: atrial fibrillation; HT: hypertension; DCM: dilated cardiomyopathy; PM: pacemaker; VD: valvular disease; AP: angina pectoris; PH: pulmonary hypertension. \#: visually scored by echocardiography with poor left ventricular ejection fraction $<30 \%$, impaired $30-<45 \%$ and normal $\geqslant 45 \%$.

two subjects reported that they snored. Even though the current authors did not find any evidence of upper airway obstruction among the studied patients, it is still possible that the position dependency in central apnoea can be explained, at least in part, by an obstructive component.

Increased circulation time and a change in automatic respiratory chemical control are the most common theories for

\begin{tabular}{lc}
\hline TABLE 2 Sleep data & \\
\hline Central AHI & $31 \pm 9$ \\
Central apnoea index & $28 \pm 11$ \\
$\quad$ Central hypopnoea index & $3 \pm 4$ \\
Obstructive AHI & $2 \pm 2$ \\
TST h & $6.5 \pm 1.0$ \\
Sleep efficiency \% & $75 \pm 12$ \\
REM sleep \% of TST & $13 \pm 6$ \\
Sleep stage 1 \% of TST & $36 \pm 20$ \\
Sleep stage 2 \% of TST & $45 \pm 15$ \\
Slow-wave sleep \% of TST & $5 \pm 5$ \\
Right side \% of TST & $33 \pm 27$ \\
Prone \% of TST & $10 \pm 18$ \\
Left side \% of TST & $26 \pm 25$ \\
Supine \% of TST & $30 \pm 24$ \\
\hline
\end{tabular}

Data are presented as mean \pm SD. AHI: apnoea-hypopnoea index; TST: total sleep time; REM: rapid eye movement. explaining Cheyne-Stokes respiration. $\mathrm{Pa}_{\mathrm{a}} \mathrm{CO}_{2}$ is slightly lower and the ventilatory response to $\mathrm{PCO}_{2}$ is increased among patients with central sleep apnoea and Cheyne-Stokes respiration [2, 4-6]. Central apnoeas are also eliminated after the inhalation of carbon dioxide [18, 19]. Furthermore, CheyneStokes respiration occurs predominantly in subjects with a low cardiac output. NAUGHTON et al. [6] reported that there is a progressive fall in AHI from sleep stages 1 and 2 to slow-wave

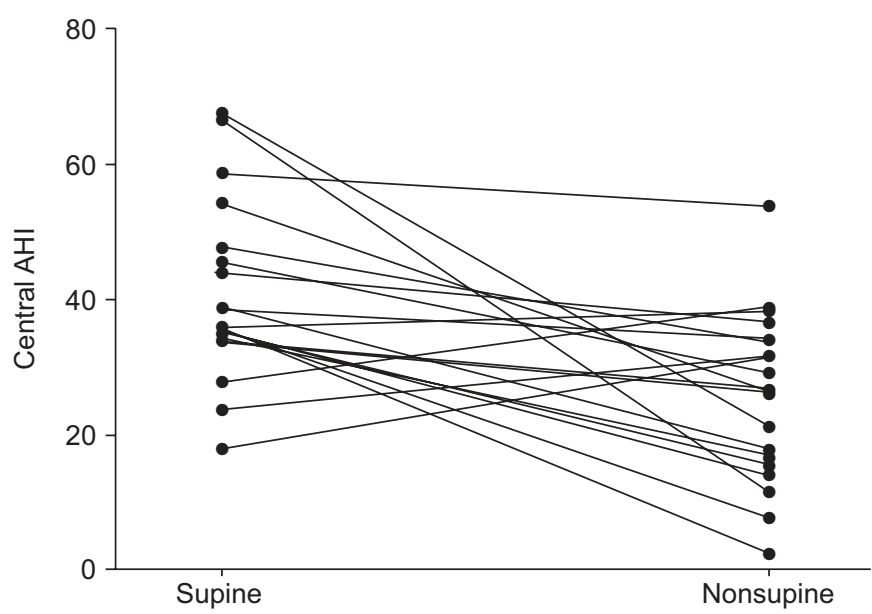

FIGURE 2. Central apnoea-hypopnoea index (AHI) in supine and nonsupine positions among patients with Cheyne-Stokes respiration 


\begin{tabular}{lccccr} 
TABLE 3 & \multicolumn{6}{l}{$\begin{array}{l}\text { Central apnoea-hypopnoea index at different } \\
\text { sleep stages and in different positions }\end{array}$} \\
& REM & Stage 1 & Stage 2 & sws & p-value \\
\hline Supine & $28 \pm 30$ & $43 \pm 15$ & $37 \pm 18$ & $23 \pm 41$ & 0.007 \\
Nonsupine & $7 \pm 12$ & $32 \pm 19$ & $30 \pm 17$ & $12 \pm 19$ & $<0.001$ \\
p-value & 0.01 & 0.04 & 0.40 & 1.0 & \\
\hline
\end{tabular}

Data are presented as mean $\pm S D$, unless otherwise stated. REM: rapid eye movement; SWS: slow-wave sleep.

sleep and REM, associated with a progressive rise in $\mathrm{Pa}, \mathrm{CO}_{2}$ among patients with Cheyne-Stokes respiration. In support of these findings, the current authors found that the central AHI was highest in stages 1 and 2, and lowest in slow-wave sleep and REM.

Since the present study is entirely descriptive, the mechanisms of supine dependence in central apnoea and Cheyne-Stokes respiration can only be speculated about. Position-dependent changes in heart function, lung function, blood gases and ventilatory response to $\mathrm{PCO}_{2}$ are possible mechanisms. Low expiratory reserve volume is related to obstructive sleep apnoea, and the expiratory reserve volume is lower in the supine position compared with the sitting position in sleep apnoea patients [20, 21]. The current authors are, however, unaware of any studies of lung function or blood gases in the supine and lateral position among patients with sleep apnoea or congestive heart failure. If lung function or blood gases are different in the supine position compared with the lateral position, the present authors think it is most probable that the lung function is reduced in the supine position, with an increase in $\mathrm{PCO}_{2}$ as a result. An increase in $\mathrm{PCO}_{2}$ should reduce the frequency of central apnoeas, and it is, therefore, thought to be unlikely that changes in lung function or blood gases could explain the current results. It is also unlikely that supinedependent Cheyne-Stokes respiration is due to changes in the ventilatory response to $\mathrm{PCO}_{2}$, since the apnoea frequency was reduced immediately when turning from the supine to the lateral position (fig. 1). It is speculated that a lower cardiac output in the supine position compared with the lateral position, which is due, for example, to a change in venous return, is a possible explanation of supine-dependent central apnoeas in Cheyne-Stokes respiration. Future studies investigating respiration, heart function, lung function, blood gases and upper airway collapsibility in the supine and lateral position among patients with Cheyne-Stokes respiration and intervention studies with changes in sleep position are desirable, as they could possibly answer some of the questions relating to mechanism raised in the present study.

In the present study, thermistors and piezo-electric belts were used to identify apnoeas and hypopnoeas. This may be regarded as a limitation, since piezo-electric belts only provide qualitative information about changes in respiration, and thermal sensors are not linearly related to airflow and generally overestimate ventilation [22]. Using this equipment instead of oesophageal pressure monitors, obstructive apnoeas can be falsely classified as central apnoeas [23]. In the present study, hypopnoeas were only scored when a 50\% reduction in amplitude was accompanied by oxygen desaturations or arousals in order to improve the accuracy [11, 12], and the risk of overestimation should, therefore, be small. In spite of this, nasal pressures and inductance plethysmography would have been more reliable [12]. All of the current patients with central apnoeas suffered from congestive heart failure and they all had central apnoeas during Cheyne-Stokes respiration, with a typical crescendodecrescendo pattern, which probably made it easier to score the central apnoeas and hypopnoeas than in the study with predominantly obstructive sleep apnoea patients [23].

Male sex, atrial fibrillation and age are known predictors of Cheyne-Stokes respiration [3, 24]. The results of the present study indicate that supine position is another factor that influences the degree of central apnoea in Cheyne-Stokes respiration. Oxygen treatment, continuous positive airway pressure treatment and noninvasive positive pressure ventilation are the main treatment modalities suggested for central sleep apnoea and Cheyne-Stokes respiration [2, 25-28]. It is possible that the avoidance of the supine position is another option in selected patients. Stroke victims often present with both obstructive and central apnoeas, but the compliance with continuous positive airway pressure is poor [29, 30]. Hemiplegia and the need for help in order to change body position in bed are common among these patients. If possible, the supine position should be avoided after a stroke to reduce the risk of all types of apnoea.

\section{Conclusion}

Sleep in the supine body position increases the frequency of apnoeas and hypopnoeas in patients with Cheyne-Stokes respiration.

\section{REFERENCES}

1 Cheyne J. A case of apoplexy, in which the fleshy part of the heart was converted into fat. Dublin hospital reports and communications in medicine and surgery 1818; 2: 216-223.

2 Franklin KA, Eriksson P, Sahlin C, Lundgren R. Reversal of central sleep apnea with oxygen. Chest 1997; 111: 163-169.

3 Javaheri S, Parker TJ, Liming JD, et al. Sleep apnea in 81 ambulatory male patients with stable heart failure. Types and their prevalences, consequences, and presentations. Circulation 1998; 97: 2154-2159.

4 Javaheri S. A mechanism of central sleep apnea in patients with heart failure. N Engl J Med 1999; 341: 949-954.

5 Franklin KA, Sandström E, Johansson G, Bålfors EM. Hemodynamics, cerebral circulation and oxygen saturation in Cheyne-Stokes respiration. J Appl Physiol 1997; 83: 1184-1191.

6 Naughton M, Benard D, Tam A, Rutherford R, Bradley TD. Role of hyperventilation in the pathogenesis of central sleep apneas in patients with congestive heart failure. Am Rev Respir Dis 1993; 148: 330-338.

7 Hanly PJ, Millar TW, Steljes DG, Baert R, Frais MA, Kryger $\mathrm{MH}$. Respiration and abnormal sleep in patients with congestive heart failure. Chest 1989; 96: 480-488.

8 Cartwright RD, Diaz E, Lloyd S. The effects of sleep posture and sleep stage on apnea frequency. Sleep 1991; 14: 351-353. 
9 Oksenberg A, Khamaysi I, Silverberg DS, Tarasiuk A. Association of body position with severity of apneic events in patients with severe nonpositional obstructive sleep apnea. Chest 2000; 118: 1018-1024.

10 Rechtschaffen A, Kales A, eds. A manual of standardized terminology, techniques and scoring system for sleep stages of human subjects. Los Angeles, Brain Information Service/Brain Research Institute, UCLA, 1968.

11 American Sleep Disorders Association. Intrinsic sleep disorders. In: Thorpy MJ, ed. The international classification of sleep disorders. Diagnostic and coding manual. Lawrence, KS, Allan Press, 1990; pp. 52-61.

12 Sleep-related breathing disorders in adults: recommendations for syndrome definition and measurement techniques in clinical research. The Report of an American Academy of Sleep Medicine Task Force. Sleep 1999; 22: 667-689.

13 Oksenberg A, Arons E, Snir D, Radwan H, Soroker N. Cheyne-Stokes respiration during sleep: a possible effect of body position. Med Sci Monit 2002; 8: 61-65.

14 Issa FG, Sullivan CE. Reversal of central sleep apnea using nasal CPAP. Chest 1986; 90: 165-171.

15 Bradley TD, McNicholas WT, Rutherford R, Popkin J, Zamel N, Phillipson EA. Clinical and physiologic heterogeneity of the central sleep apnea syndrome. Am Rev Respir Dis 1986; 134: 217-221.

16 Alex CG, Önal E, Lopata M. Upper airway occlusion during sleep in patients with Cheyne-Stokes respiration. Am Rev Respir Dis 1986; 133: 42-45.

17 Badr MS, Toiber F, Skatrud JB, Dempsey J. Pharyngeal narrowing/occlusion during central sleep apnea. J Appl Physiol 1995; 78: 1806-1815.

18 Steens RD, Millar TW, Xiaoling S, et al. Effect of inhaled 3\% $\mathrm{CO}_{2}$ on Cheyne-Stokes respiration in congestive heart failure. Sleep 1994; 17: 61-68.

19 Andreas S, Weidel K, Hagenah G, Heindl S. Treatment of Cheyne-Stokes respiration with nasal oxygen and carbon dioxide. Eur Respir J 1998; 12: 414-419.

20 Sériès F, Cormier Y, La Forge J. Role of lung volumes in sleep apnoea-related oxygen desaturation. Eur Respir J 1989; 2: 26-30.
21 Appelberg J, Nordahl G, Janson C. Lung volume and its correlation to nocturnal apnoea and desaturation. Respir Med 2000; 94: 233-239.

22 Farre R, Montserrat JM, Rotger M, Ballester E, Navajas D. Accuracy of thermistors and thermocouples as flowmeasuring devices for detecting hypopnoeas. Eur Respir J 1998; 11: 179-182.

23 Boudewyns A, Willemen M, Wagemans M, De Cock W, Van de Heyning P, De Backer W. Assessment of respiratory effort by means of strain gauges and esophageal pressure swings: a comparative study. Sleep 1997; 20: 168-170.

24 Sin DD, Fitzgerald F, Parker JD, Newton G, Floras JS, Bradley TD. Risk factors for central and obstructive sleep apnea in 450 men and women with congestive heart failure. Am J Respir Crit Care Med 1999; 160: 1101-1106.

25 Hanly PJ, Millar TW, Steljes DG, Baert R, Frais MA, Kryger $\mathrm{MH}$. The effect of oxygen on respiration and sleep in patients with congestive heart failure. Ann Intern Med 1989; 111: 777-782.

26 Andreas S, Clemens C, Sandholzer H, Figulla HR, Kreuzer H. Improvement of exercise capacity with treatment of Cheyne-Stokes respiration in patients with congestive heart failure. J Am Coll Cardiol 1996; 27: 1486-1490.

27 Sin DD, Logan AG, Fitzgerald FS, Liu PP, Bradley TD. Effects of continuous positive airway pressure on cardiovascular outcomes in heart failure patients with and without Cheyne-Stokes respiration. Circulation 2000; 102: 61-66.

28 Teschler H, Döhring J, Wang YM, Berthon-Jones $M$. Adaptive pressure support servo-ventilation. A novel treatment for Cheyne-Stokes respiration in heart failure. Am J Respir Crit Care Med 2001; 164: 614-619.

29 Sandberg O, Franklin KA, Bucht G, Gustafson Y. Sleep apnea, delirium, depressed mood, cognition, and ADL ability after stroke. J Am Geriatr Soc 2001; 49: 391-397.

30 Sandberg O, Franklin KA, Bucht G, Gustafson Y. Nasal continuous positive airway pressure in stroke patients with sleep apnoea: a randomized treatment study. Eur Respir J 2001; 18: 630-634. 